Определение тактики лечения острой хирургической патологии органов брюшной полости и забрюшинного пространства у больных с терминальной стадией ВИЧ-инфекции на основании данных многосрезовой компьютерной томографии и магнитно-резонансной томографии

Климова Н.В. ${ }^{2}$, Гаус А.А. ${ }^{1}$, Дарвин В.В. ${ }^{1}$, Ильина У.Б. ${ }^{2, ~}{ }^{*}$

${ }^{1}$ БУ ВО ХМАО - Югры «Сургутский государственный университет», пр-т Ленина, 1, Сургут, 628412, Российская Федерация

${ }^{2}$ БУ ХМАО - Югры «Сургутская окружная клиническая больница», ул. Энергетиков, 14, Сургут, 628408, Российская Федерация

\begin{abstract}
Резюме
Цель исследования - определение тактики лечения острой хирургической патологии у больных с терминальной стадией ВИЧ-инфекции с применением данных высокоинформативных визуализационных методов диагностики - многосрезовой компьютерной томографии (МСКТ) и магнитно-резонансной томографии (МРТ).

Материал и методы. За период с 2008 по 2016 г. были обследованы 425 больных СПИДом (мужчин 320, женщин - 105), находящихся на лечении в хирургических стационарах Сургутской окружной клинической больницы, с использованием МСКТ (Toshiba Aquilion 64, Япония) и MPT (Siemens 1,5T Magnetom Essenza, Германия) для выявления как местной хирургической, так и общей микст-патологии. Результаты. При анализе острых хирургических заболеваний органов брюшной полости и забрюшинного пространства у больных с терминальной стадией ВИЧ-инфекции была определена зависимость тактики лечения от клинико-диагностических данных.

Выводы. 1. МСКТ и МРТ являются высокоинформативными методами диагностики острой хирургической патологии у больных с терминальной стадией ВИЧ-инфекции. 2. При острой хирургической патологии у больных с терминальной стадией ВИЧ-инфекции на фоне генерализации оппортунистической инфекции предпочтительно выполнение малоинвазивных хирургических вмешательств.

Ключевые слова: острая хирургическая патология; синдром приобретенного иммунодефицита; микстинфекция; многосрезовая компьютерная томография; магнитно-резонансная томография.

Конфликт интересов. Авторы заявляют об отсутствии конфликта интересов.

Финансирование. Исследование не имело спонсорской поддержки.

Для цитирования: Климова Н.В., Гаус А.А., Дарвин В.В., Ильина У.Б. Определение тактики лечения острой хирургической патологии органов брюшной полости и забрюшинного пространства у больных с терминальной стадией ВИЧ-инфекции на основании данных многосрезовой компьютерной томографии и магнитно-резонансной томографии. Вестник рентгенологии и радиологии. 2019; 100 (6): 355-62. https://doi.org/ 10.20862/0042-4676-2019-100-6-355-362
\end{abstract}

Статья поступила 11.01.2018 П После доработки 06.03.2019 Принята к печати 04.04.2019

\title{
Determination of Treatment Policy for Acute Surgical Disease of the Abdominal Cavity and Retroperitoneal Space in Patients with Late-Stage HIV Infection According to Multislice Computed Tomography and Magnetic Resonance Imaging Data
}

\author{
Natal'ya V. Klimova², Anna A. Gaus1, Vladimir V. Darvin'1, Ul'yana B. II'ina ${ }^{2, ~ *}$ \\ ${ }^{1}$ Surgut State University, \\ prospekt Lenina, 1, Surgut, 628412, Russian Federation \\ 2 Surgut District Clinical Hospital, \\ ul. Energetikov, 14, Surgut, 628408, Russian Federation
}




\section{Abstract}

Objective: to determine treatment policy for an acute surgical disease in patients with late-stage HIV infection diagnosed using the data of the highly informative imaging techniques multislice computed tomography (MSCT) and magnetic resonance imaging (MRI).

Material and methods. In 2008 and 2016, the authors examined 425 patients (320 men and 105 women) with acquired immunodeficiency syndrome (AIDS) who were treated at the surgical units of the Surgut Regional Clinical Hospital, by using the data of MSCT (Toshiba Aquilion 64, Japan) and MRI (Siemens 1,5T Magnetom Essenza, Germany) in identifying both local surgical and general mixed diseases.

Results. Analysis of acute surgical diseases of the abdominal cavity and retroperitoneal space in patients with late-stage HIV infection determined that the treatment policy in this category of patients depended on clinical diagnostic data.

Conclusions. 1. MSCT and MRI are highly informative techniques in diagnosing acute surgical diseases in patients with late-stage HIV infection. 2. The course of an acute surgical disease in patients with late-stage HIV infection in the presence of generalized opportunistic infection makes it preferable to perform minimally invasive surgical interventions.

Keywords: acute surgical disease; acquired immunodeficiency syndrome; mixed infection; multislice computed tomography; magnetic resonance imaging.

Conflict of interest. The authors declare no conflict of interest.

Funding. The study had no sponsorship.

For citation: Klimova N.V., Gaus A.A., Darvin V.V., Il'ina U.B. Determination of treatment policy for acute surgical disease of the abdominal cavity and retroperitoneal space in patients with late-stage HIV infection according to multislice computed tomography and magnetic resonance imaging data. Journal of Radiology and Nuclear Medicine. 2019; 100 (6): 355-62 (in Russ.). https://doi.org/10.20862/0042-46762019-100-6-355-362

Received 11.01.2018

Revised 06.03.2019

Accepted 04.04.2019

\section{Введение}

Клинико-лабораторная диагностика хирургической патологии у больных с терминальной стадией ВИЧ-инфекции является крайне затруднительной, что обусловлено замаскированностью конкурирующей патологией и слабым иммунным ответом [1]. В связи с этим местный хирургический процесс любой локализации у больных СПИДом на фоне множества оппортунистических инфекций протекает атипично. Кроме того, полиорганность, множественность поражения, склонность к рецидивированию влечет за собой сложности в диагностике гнойной патологии у этой категории больных. Наличие неспецифичной картины микст-инфекции и оппортунистических опухолей [2] является причиной неадекватного лечения и часто приводит к летальному исходу $[2,3]$. В настоящее время хирурги, определяя показания к хирургическому лечению, сталкиваются с генерализованным внелегочным туберкулезом, лимфомами самой разной локализации, саркомой кишечника. Кроме того, острая хирургическая патология может протекать на фоне атипичных опухолей: саркомы Капоши, лимфомы, приводящих к перфорации кишечника, кровотечениям, кишечной непроходимости [1, 4-6].

Целью нашего исследования стало определение тактики лечения острой хирургической патологии у больных с терминальной стадией ВИЧ-инфекции с применением данных высокоинформативных визуализационных методов диагностики многосрезовой компьютерной томографии (МСКТ) и магнитно-резонансной томографии (МРТ).

\section{Материал и методы}

За период с 2008 по 2016 г. нами были обследованы 425 больных СПИДом (мужчин - 320, женщин - 105), находящихся на лечении в хирургических стационарах Сургутской окружной клинической больницы, с использованием MCKT (Toshiba Aquilion 64, Япония) и МРT (Siemens 1,5T Magnetom Essenza, Германия) для выявления как местной хирургической, так и общей микст-патологии. Наиболее доступный и информативный метод лучевой диагностики патологии у ВИЧ-инфицированных многосрезовая компьютерная томография. МСКТ грудной клетки и брюшной полости по традиционной методике, с болюсным трехфазным усилением была выполнена в $97 \%$ случаев $(n=413)$. Другой информативной методикой обследования органов брюшной полости и забрюшинного пространства являлась магнитно-резонансная томография, использованная в $30 \%$ случаев $(n=126)$. МРТ брюшной полости в режиме Т1-ВИ и Т2-ВИ была дополнена программами с подавлением сигнала от жира и диффузионно-взвешенными изображениями (DWI), с обязательным болюсным контрастным усилением препаратами гадолиния.

\section{Результаты}

Возможности МСКТ позволяли достоверно оценивать объем, характер и локализацию воспалительного экссудата, состояние кишечной стенки, брыжейки, брюшины, мезентериальных лимфоузлов, выявлять не только наличие перфорации кишки, но и уточнять ее локализацию, обнаруживать внеорганные абсцессы брюшной полости, 
включая мелкие межпетельные. Метод МРТ с контрастным усилением высокоинформативен в диагностике очаговой деструкции поджелудочной железы, абсцессов селезенки. Использование гепатоспецифического препарата характеризуется высокой чувствительностью $(99,5 \%)$ при диагностике деструктивных процессов печени, поиске гепатобилиарных и подкапсульных свищей; специфичность метода составляет 97\%. Исследования велись по традиционной методике. Применение именно этого контрастного препарата позволяло дифференцировать гнойные процессы в печени на фоне существующих микст-инфекций.

у больных СПИДом абсцессы печени встречаются довольно часто - в 12,5\% случаев всех острых хирургических патологий $(n=53)$. При этом размеры воспалительных очагов варьировали от 1 до 5 см, у половины обследованных они были множественные. Возможности МСКТ при диагностике абсцессов печени ограничены визуализацией гиподенсивной зоны различной локализации размером более 10 мм. При этом капсула длительное время четко не определялась без контрастного болюсного усиления. На МРТ визуализируемая зона инфильтрации в печени значительно превышает таковую на МСКТ, четко выявляется капсула абсцесса, ее толщина и структура, даже без контрастного усиления. Кроме того, достоверно определялись и другие гнойники в печени и поджелудочной железе, которые не выявлялись при МСКТ.

Топическое соотношение абсцесса с сосудами печени определяется при контрастном болюсном усилении гепатоспецифическим препаратом в аортальную и портальную фазы, в гепатобилиарную фазу четко выявлялись гепатобилиарные свищи $63 \%$ всех случаев абсцессов $(n=33)$. Диагностика данных свищей имеет принципиальное клиническое значение, поскольку наличие дренирования абсцессов в выносящую билиарную систему свидетельствует о благоприятном течении гнойного процесса и отсутствии показаний для хирургического лечения. Абсцессы печени - достаточно частая хирургическая патология у больных СПИДом - 12,5\% $(n=53)$ случаев в нашем исследовании $[2,7,8]$. Нагноительные процессы в печени у больных с терминальной стадией ВИЧ-инфекции чаще отличаются множественностью поражения, а также довольно крупными размерами полостей деструкции (до 10-15 см) [9, 10]. В таких случаях, независимо от генерализации оппортунистических инфекций, методом выбора лечения является хирургический наружное дренирование под КТ-контролем (11,5\% $(n=49)$ случаев) или, при его невозможности или неэффективности, лапаротомия и санация патологического очага (3,3\% ( $n=14)$ случаев).

Возможности МРТ в диагностике небольших (менее 3 см) абсцессов печени значительно выше, чем МСКТ, особенно с использованием гепатоспецифического контрастного препарата (примовист). Способность этого контрастного вещества проникать в желчевыделительные пути также позволяет достоверно выявлять гепатобилиарные свищи при абсцедировании. Для решения тактических вопросов лечения очень важно оценить связь абсцесса с дренирующим протоком. Его наличие свидетельствует о благоприятном течении нагноительного процесса: дренирование абсцесса в выносящий проток значительно улучшает клинико-лабораторную картину заболевания и способствует выздоровлению. В этом случае хирургическое лечение больным не требовалось.

Абсцессы селезенки у больных с терминальной стадией ВИЧ-инфекции чаще всего являлись случайными находками (8\% $(n=33)$ случаев) [9, 11], поскольку замаскированы проявлениями генерализованных оппортунистических инфекций. Они практически всегда выглядели как мелкие (до 10-15 мм) множественные (более 3 шт) субкапсулярные округлые образования с четко выраженной капсулой. Метод МРТ с контрастным усилением в данном случае является приоритетным, поскольку позволяет более достоверно дифференцировать инфаркты и абсцессы селезенки (рис. 1) (8\% $(n=34)$ случаев). Если абсцессы селезенки визуализируются на КТ как мелкие множественные округлые образования на фоне выраженной спленомегалии, показано проведение спленэктомии. Если же имеет место крупная полость деструкции в селезенке (более 3 см), целесообразно выполнять наружное дренирование под КТ-контролем. При его неэффективности проводятся лапаротомия и ликвидация патологического очага с последующим дренированием области оперативного вмешательства $(0,7 \%(n=3)$ случаев).

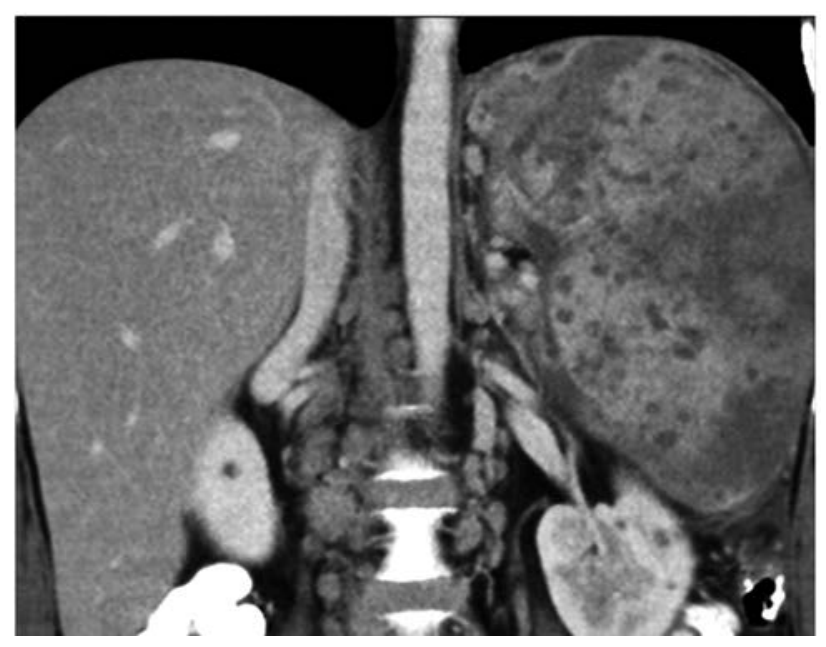

Рис. 1. Исследование брюшной полости больного К., 27 лет: МРТ брюшной полости, коронарный срез, режим Т2-ВИ с подавлением сигнала от жира. Визуализируются множественные сформированные мелкие абсцессы паренхимы селезенки 
Клиническая картина при абсцессах почек у больных СПИДом (5\% $(n=22)$ случаев в нашем исследовании) отличалась особой тяжестью, что было обусловлено микст-патологией генерализованных инфекций и деструктивным процессом в почках, который может привести к почечной недостаточности. Хирургическое лечение (малоинвазивное дренирование под КТ-контролем) проводилось при отсутствии генерализованных инфекций (туберкулеза, пневмоцистной пневмонии, токсоплазмоза, микоза и т. д.). Особенно ситуация осложнялась при формировании внеорганного забрюшинного нагноения - 7\% $(n=30)$ случаев (рис. 2). Тяжесть состояния у этих больных была обусловлена сепсисом и явлениями почечной недостаточности. Хирургическое лечение проводилось всем больным после стабилизации состояния и включало дренирование и санацию забрюшинного пространства независимо от наличия генерализованных оппортунистических инфекций.

Наиболее частой острой хирургической патологией брюшной полости и забрюшинного пространства у пациентов с терминальной стадией ВИЧ-инфекции являются внеорганные абсцессы. По данным разных авторов, абсцессы брюшной полости выявляются в 25-50\% случаев [6, 7]. В нашем исследовании внеорганные абсцессы у пациентов с ВИЧ-инфекцией были выявлены в 43\% $(n=183)$ случаев при проведении МСКТ с использованием мультипланарных реконструкций. Размер абсцессов достигал 5 см. Достоверно выявляются топическая, в том числе межпетельная, локализация абсцессов, их капсула, связь со стенкой кишки, в некоторых случаях свищи (10\% ( $n=42)$ случаев). Данные МРТ в отношении диагностики внеорганных абсцессов менее убедительны в связи с наличием динамичес-

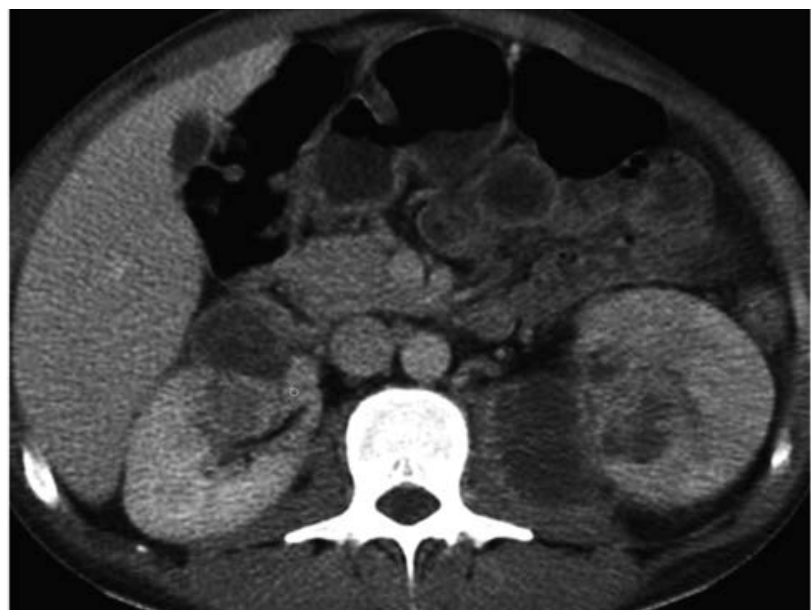

Рис. 2. Исследование брюшной полости больного И., 36 лет: МСКТ брюшной полости с контрастным болюсным усилением, отсроченная фаза контрастирования, аксиальный срез. Визуализируются множественные абсцессы почек, паранефральные абсцессы ких артефактов от перистальтики кишечника, большей толщины скана.

Клиническая картина абсцессов брюшной полости у больных с терминальной стадией ВИЧ-инфекции (43\% ( $n=183)$ случаев) зачастую не соответствует тяжести состояния пациента. При небольших абсцессах (до 1-3 см) этим пациентам требовались малоинвазивные хирургические вмешательства (дренирование), при крупных (более 3 см) - лапаротомия, причем зачастую повторная (15\% ( $n=63)$ случаев). Внеорганные забрюшинные абсцессы встречались реже (7\% $(n=30)$ случаев), чем абсцессы в брюшной полости (рис. 3) [12]. Однако клинически они протекали гораздо тяжелее, поскольку сопровождались почечной недостаточностью. У таких пациентов практически всегда наблюдаются явления сепсиса. Интраоперационная хирургическая тактика при забрюшинных абсцесcax у больных с терминальной стадией ВИЧ-инфекции должна включать первоначально - ликвидацию патологического очага, затем - санацию и дренирование забрюшинного пространства.

Псоас-абсцессы у больных СПИДом - достаточно редкая хирургическая патология (2\% $(n=8)$ случаев в нашем исследовании). Встречались они преимущественно у женщин, не представляли сложностей в диагностике, протекали значительно легче, чем забрюшинные абсцессы. Однако истинные размеры и толщину капсулы можно было выявить только при внутривенном контрастировании.

Панкреонекрозы у больных с терминальной стадией ВИЧ-инфекции (17\% $(n=72)$ случаев) зачастую имеют туберкулезную этиологию в фазе генерализации (12\% ( $n=51)$ случаев). Однако протекать данная инфекция может по-разному. При милиарном некрозе тяжесть состояния обусловлена практически тотальной деструкцией подже-

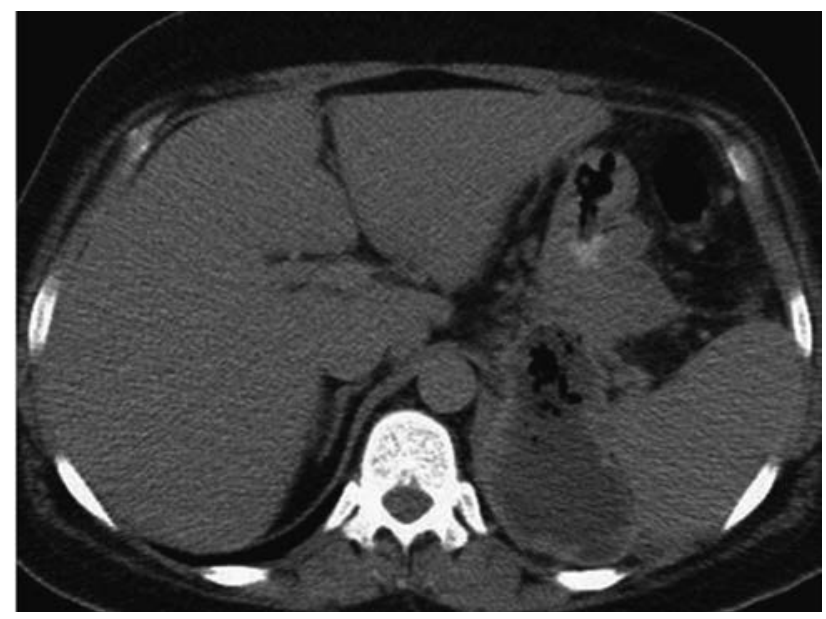

Рис. 3. Исследование брюшной полости больного 4., 38 лет: МСКТ брюшной полости и забрюшинного пространства с контрастным болюсным усилением, нативная фаза сканирования, аксиальный срез. Визуализируется забрюшинный абсцесс слева 
лудочной железы с массивным скоплением воспалительной жидкости как в брюшной полости, так и (в виде отдаленных затеков) в малом тазу. У пациентов наблюдались явления сепсиса. Морфологически в брюшной полости определяется генерализованная милиарная паренхиматозная и мезентериальная диссеминация. Этой категории пациентов требуются программированная лапаротомия, иногда повторная, активное дренирование и санация брюшной полости. Если же туберкулезное воспаление протекало по типу казеозного некроза, то наблюдались признаки «творожистой» деструкции поджелудочной железы. В таких случаях больным проводили малоинвазивное дренирование и санацию брюшной полости $(7,8 \%(n=33)$ случаев). При туберкулезном панкреонекрозе наблюдалась выраженная деструкция паренхимы поджелудочной железы с наличием значительных, достигающих полости малого таза затеков воспалительной жидкости. Отдельные секвестры паренхимы железы могли быть крупными и множественными. При этом разрушенная паренхима органа выглядела пятнистой за счет милиарной диссеминации. Подобная милиарная диссеминация наблюдалась в легких, печени и брыжейке тонкой кишки у $3 \%(n=13)$ пациентов. Кроме того, на серозных оболочках могли наблюдаться характерные «творожистые массы», которые на МРТ выглядят как распространенный причудливой формы процесс с повышенным МР-сигналом во всех импульсных последовательностях. При контрастном усилении выявлялось патологическое интенсивное накопление контрастного вещества в виде очагов диссеминации по периферии, чаще в венозную фазу, как на КТ, так и МРT.

Мезентериальная лимфаденопатия наблюдалась практически в 100\% случаев и имела разную степень выраженности, при этом лимфоузлы могли достигать 3 см в диаметре, контуры их были нечеткие, внутренняя структура не сохранена, жировой центр не дифференцируется. Гораздо реже встречался токсоплазменный панкреонекроз - в 2,6\% $(n=11)$ случаев. Морфологически в биоптатах брюшины, ткани поджелудочной железы и воспалительной жидкости выявлялись характерные токсоплазменные цисты. На компьютерных томограммах они выглядели как множественные кистоподобные образования в зоне деструкции диаметром до 10 мм, часто с наличием кальцинации в капсуле. При этом экссудативные изменения брюшной полости были выражены слабо. При микотическом воспалении поджелудочной железы $(2,6 \%(n=11)$ случаев) морфологически в области деструкции были видны «ветвистые гифы (нити) мицелия», а также микроабсцессы размером до 2-3 мм. По данным КТ визуализировалась мелкоячеистая инфильтрация клетчатки брюшной полости, имити- рующая «соты» (рис. 4), на фоне минимальных экссудативных изменений. У обоих категорий этих больных требуется проведение малоинвазивного дренирования и санации брюшной полости.

Особенно тяжело у больных СПИДом протекали перитониты (23\% ( $n=98)$ случаев). При анализе морфологических данных туберкулезная инфекция брюшной полости у данной категории больных присутствовала всегда. В $61 \%$ случаев это было монотуберкулезное поражение ( $n=60)$, в 36\% - бактериальная микст-инфекция с наличием туберкулеза $(n=35)$, в 3\% - микст-патология при сочетании лимфомы и туберкулеза брюшной полости $(n=3)$.

В процессе исследования в зависимости от течения перитонита нами было выделено три группы больных с терминальной стадией ВИЧ-инфекции.

Первая группа - 60 (14\%) больных с асцит-перитонитом, проявляющимся выраженным экссудативным воспалительным процессом в брюшной и грудной полостях, с наличием интраоперационно подтвержденной милиарной диссеминации брюшины, с тяжелым рецидивирующим затяжным течением. По данным КТ-исследования выявлялось большое количество свободной жидкости в брюшной и грудной полостях, за счет чего клетчатка брюшной полости визуализировалась слабо. При контрастном усилении брюшина брыжейки выглядела неравномерно утолщенной, «бугристой» за счет милиарной диссеминации (подтвержденной во время операции), интенсивно накапливала контрастное вещество в венозную фазу. Петли кишечника обычно были резко расширены, содержали большое количество жидкости и газа. Стенка тонкой кишки была утолщена, определялось скопление жидкости между ее слоями. Лимфоузлы визуализировались неструктурными, значительно увеличенными, спаянными в конгломераты. Однако явных признаков перфораций кишеч-

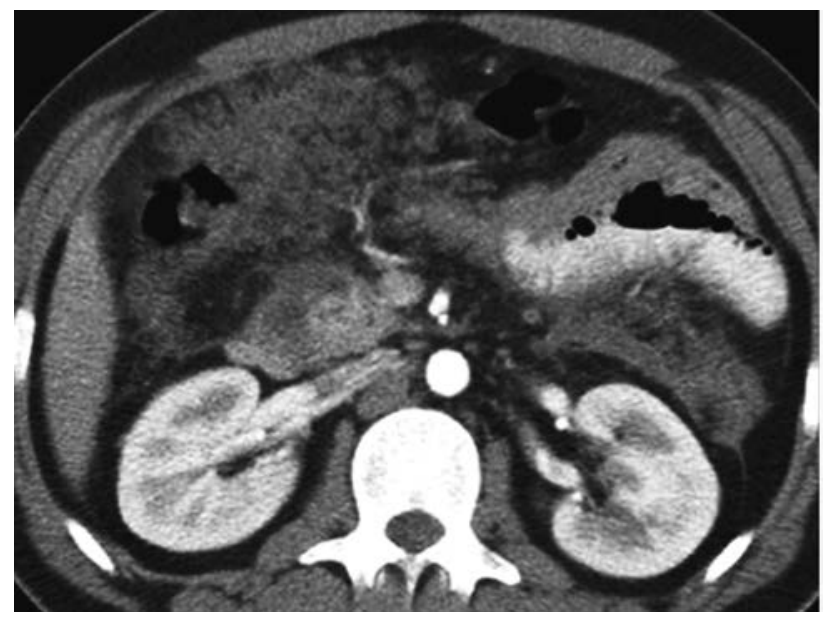

Рис. 4. Исследование брюшной полости больного Л., 24 лет: МСКТ брюшной полости с контрастным болюсным усилением, артериальная фаза сканирования, аксиальный срез. Визуализируется кандидозный панкреонекроз 
ника не отмечено. Морфологически в свободной жидкости, биоптатах брюшины, стенке кишки, лимфоузлах у этой категории пациентов выявлялись микобактерии туберкулеза. Спаечный процесс был не выражен, в связи с чем отграничения жидкости не наблюдалось. Клиническая картина отличалась тяжестью состояния в связи с наличием тяжелого сепсиса, полиорганной недостаточности и явлений рецидивирующего полисерозита. Кроме того, у этих пациентов наряду с перитонитом часто имели место плеврит (эмпиема плевы) - 10\% $(n=42)$ случаев и экссудативный перикардит $4,7 \%(n=20)$ случаев. Учитывая, что при этой патологии у больных с терминальной стадией ВИЧ-инфекции выявлялось большое количество свободной жидкости в брюшной и грудной полостях, им требовались программированная релапаротомия и повторное дренирование плевральной полости. Интраоперационная тактика в таких случаях должна включать ликвидацию патологического очага, санацию и дренирование брюшной полости. Послеоперационная летальность составляет до $40 \%$.

Вторая группа - 35 (8\%) больных с перитонитами на фоне рецидивирующих перфораций стенки кишки, с массивным гнойно-казеозным воспалением брюшины, множественными межпетельными скоплениями воспалительной жидкости, наличием внутренних кишечных свищей. Интраоперационно выявлялось массивное гнойно-казеозное воспаление кишечной стенки. Морфологически в содержимом жидкостных скоплений, биоптатах брюшины, стенке кишки, лимфоузлах - обширная микст-инфекция (грибковая, ЦМВ) с наличием микобактерий туберкулеза. При этом жидкость в брюшной полости визуализировалась в виде отграниченных множественных межпетельных скоплений (рис. 5), также определялись и межкишечные свищи. Тяжесть течения заболевания у данной категории пациентов была обусловлена недостаточной эффективностью проводимых лечебных мероприятий на фоне рецидивов воспалительных деструктивных процессов в брюшной полости, повторных перфораций кишечной стенки и формирования дополнительных свищей. Жидкостные скопления у этой категории пациентов располагались преимущественно вдоль толстой кишки и содержали пузырьки свободного газа, что свидетельствует о возможной перфорации. Мезентериальные лимфоузлы были неструктурные, значительно увеличенные, с признаками центрального распада. Наличие рецидивирующих перфораций стенки кишки, формирование внутренних кишечных свищей и дополнительных межпетельных скоплений воспалительной жидкости обусловили необходимость повторного ушивания свищей ЖКТ, а в тяжелых случаях - выведения энтеролибо колостом (12,5\% случаев), санации и дрени-

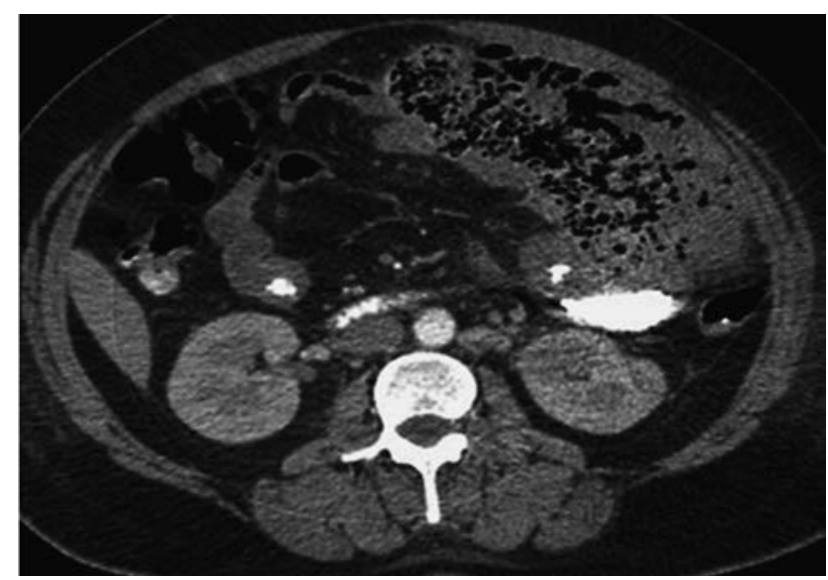

Рис. 5. Исследование брюшной полости больного Ф., 37 лет: МСКТ брюшной полости с контрастным болюсным усилением, артериальная фаза сканирования, аксиальный срез. Визуализируется абсиесс большого сальника слева

рования брюшной полости. Послеоперационная летальность составила $25 \%$.

Третья группа - 3 (1\%) больных с «сухим» отграниченным перитонитом и наличием конгломератов увеличенных мезентериальных лимфоузлов. По данным КТ жидкость в брюшной полости визуализировалась в небольшом количестве, чаще была осумкована. При этом определялось внеорганное массивное объемное образование, неотделимое от стенки кишки, имитирующее конгломерат мезентериальных лимфоузлов. Однако в отличие от последнего контуры лимфоидной пролиферации при лимфоме были нечеткие, неровные, дифференциации отдельных лимфоузлов не наблюдалось, она интенсивно и довольно гомогенно накапливала контрастное вещество в венозную и отсроченную фазы. У этих больных интраоперационно были выявлены массивное наложение фибрина по брюшине с распространенной лимфомой брюшной полости и вовлечением в процесс стенки кишки. Первоначально данная КТ-картина часто расценивается как лимфома. Однако при морфологическом исследовании в воспалительной жидкости могли быть определены и микобактерии туберкулеза. Явления перитонита у больных этой группы были выражены слабо на фоне генерализации опухолевого процесса и диагностировались интраоперационно [1, 4]. Хирургическое вмешательство в таких случаях выполнялось экстренно, на фоне прорастания опухолью стенки кишки и развития кишечной непроходимости, и включало паллиативное выведение коло- или энтеростом, а также малоинвазивное дренирование брюшной полости.

\section{Обсуждение}

Тактика хирургического лечения у больных с острой хирургической патологией на фоне терминальной стадии ВИЧ-инфекции в зависимости от клинико-диагностических данных приведена в таблице. 
Тактика хирургического лечения у больных с острой хирургической патологией

\begin{tabular}{|c|c|}
\hline Острая хирургическая патология & Тактика лечения \\
\hline $\begin{array}{l}\text { Мелкие абсцессы печени с наличием } \\
\text { гепатобилиарного свища }\end{array}$ & $\begin{array}{l}\text { Хирургического лечения не требуется. Адекватная антибактериальная } \\
\text { терапия }\end{array}$ \\
\hline Крупные абсцессы печени & $\begin{array}{l}\text { Наружное дренирование под КТ-контролем, при его невозможности } \\
\text { или неэффективности - лапаротомия и санация патологического очага }\end{array}$ \\
\hline Множественные милиарные абсцессы селезенки & Спленэктомия \\
\hline Крупный абсцесс селезенки (более 3 см) & $\begin{array}{l}\text { Наружное дренирование под КТ-контролем, при его неэффективности - } \\
\text { лапаротомия и ликвидация патологического очага }\end{array}$ \\
\hline Внеорганные абсцессы брюшной полости & $\begin{array}{l}\text { Мини-лапаротомия с санацией брюшной полости, при неэффективности - } \\
\text { лапаротомия }\end{array}$ \\
\hline Псоас-абсцессы & $\begin{array}{l}\text { Наружное дренирование под КТ-контролем, при его неэффективности - } \\
\text { лапаротомия и ликвидация патологического очага }\end{array}$ \\
\hline Тотальный панкреонекроз & $\begin{array}{l}\text { Программированные мини-релапаротомии, дренирование и санация, } \\
\text { оментостомия }\end{array}$ \\
\hline Субтотальный панкреонекроз & Дренирование и санация брюшной полости \\
\hline Асцит-перитонит & Программированные мини-релапаротомии, дренирование и санация \\
\hline $\begin{array}{l}\text { Перитонит на фоне рецидивирующих } \\
\text { перфораций кишки }\end{array}$ & $\begin{array}{l}\text { Лапаротомия, ушивание перфораций, дренирование и санация } \\
\text { (еюно-, колостомия) }\end{array}$ \\
\hline Абсцесс почек & $\begin{array}{l}\text { Дренирование и санация при отсутствии генерализованных } \\
\text { оппортунистических инфекций }\end{array}$ \\
\hline Забрюшинные внеорганные абсцессы & $\begin{array}{l}\text { Дренирование и санация независимо от наличия генерализованных } \\
\text { оппортунистических инфекций }\end{array}$ \\
\hline Кишечная непроходимость при лимфомах & $\begin{array}{l}\text { Лапаротомия, выведение коло- или энтеростом. Малоинвазивное } \\
\text { дренирование брюшной полости }\end{array}$ \\
\hline
\end{tabular}

\section{Выводы}

1. МСКТ и МРТ являются высокоинформативными методами диагностики острой хирургической патологии у больных с терминальной стадией ВИЧ-инфекции.
2. При острой хирургической патологии у больных с терминальной стадией ВИЧ-инфекции на фоне генерализации оппортунистической инфекции предпочтительно выполнение малоинвазивных хирургических вмешательств.

\section{Литература}

1. Савельева Т.В., Трофимова Т.Н., Гинзберг Д.М. Особенности абдоминальной патологии у ВИЧ-инфицированных с клинической картиной «острого живота» - возможности лучевых методов диагностики (МСКТ и МРТ). ВИЧ-инфекция и иммуносупрессии. 2011; 2 (3): 31-6.

2. Kwara A., Carter E.J., Rich J.D., Flanigan T.P. Development of opportunistic infections after diagnosis of active tuberculosis in HIV-infected patients. AIDS Patient Care STDS. 2004; 18 (6): 341-7.

3. Алексеева Л.П. Особенности выявления, клинического течения и лечения больных туберкулезом и ВИЧ-инфекцией: Автореф. дис. ... канд. мед. наук. М.; 2008.

4. Scoazec J.Y., Degott C., Brousse N. Non-Hodgkin's lymphoma presenting as a primary tumor of the liver: presentasion, diagnosis and outeoma in eight patients. Heopatology. 1991; 13 (5): 870-5.

5. Литвинова Н.Г., Кравченко А.В., Шагильдян В.И., Груздев Б.М. Течение туберкулеза и особенности его диагностики у больных с ВИЧ-инфекцией на поздних стадиях заболевания. В кн.: Сборник материалов VIII Российского съезда фтизиатров. М.; 2007: 371-2.

6. Пантелеев А.М., Савина Т.А., Супрун Т.Ю. Внелегочный туберкулез у ВИЧ-инфицированных. Туберкулез и болезни легких. 2007; 84 (7): 16-9.
7. Crothers K., Thompson B.W., Burkhardt K., Morris A., Flores S.C., Diaz P.T. et al. HIV-associated lung infections and complications in the era of combination antiretroviral therapy. Lung HIV Study. Seattle, Washington: University of Washington; 2011; 19.

8. Rasokat H.H., Hautkr Z. Skin changes in drug-dependent patients. Probl. Drug Depend. 1990; 65 (4): 351-4.

9. Савельева Т.В., Трофимова Т.Н., Рассохина В.В. Лучевая диагностика изменений брюшной полости и забрюшинного пространства у ВИЧ-инфицированных пациентов. ВИЧ-инфекция и иммуносупрессии. 2010; 2 (3): 15-22.

10. Скопин М.С., Батыров Ф.А., Корнилова 3.Х. Распространенность туберкулеза органов брюшной полости и особенности его выявления. Туберкулез и болезни легких. 2007; 84 (1): 22-6.

11. Гаус А.А., Климова Н.В., Дарвин В.В., Зинченко О.А. Возможности мультиспиральной компьютерной томографии в обосновании выбора хирургической тактики лечения перитонита у больных с терминальной стадией ВИЧ-инфекции. Вестник Сургутского государственного универcumema. 2016; 4 (30): 17-22.

12. Блувштейн Г.А., Мозеров С.А., Кулаков А.А. Клинико-морфологические аспекты хирургических ошибок и осложнений у больных ВИЧ/СПИД. Известия высших учебных заведений. Поволжский регион. Медицинские науки. 2010; 4 (16): 61-72. 


\section{References}

1. Savel'eva T.V., Trofimova T.N., Ginzberg D.M. Features of abdominal pathology HIV-positive people with a clinical picture of "a sharp stomach" have possibilities of beam methods of diagnostics (MSCT and MRI). HIV Infection and Immunosuppressive Disorders. 2011; 2 (3): 31-6 (in Russ.).

2. Kwara A., Carter E.J., Rich J.D., Flanigan T.P. Development of opportunistic infections after diagnosis of active tuberculosis in HIV-infected patients. AIDS Patient Care STDS. 2004; 18 (6): 341-7.

3. Alekseeva L.P. Features of identification, clinical current and treatment of TB patients and HIV infection. Cand. Med. Sc. Thesises of Diss. Moscow; 2008 (in Russ.).

4. Scoazec J.Y., Degott C., Brousse N. Non-Hodgkin's lymphoma presenting as a primary tumor of the liver: presentasion, diagnosis and outeoma in eight patients. Heopatology. 1991; 13 (5): 870-5.

5. Litvinova N.G., Kravchenko A.V., Shagil'dyan V.I., Gruzdev B.M. The course of tuberculosis and feature of its diagnostics at patients with HIV infection at late stages of a disease. In: Collection of materials VIII of the Russian congress of phthisiatricians. Moscow; 2007: 371-2 (in Russ.).

6. Panteleev A.M., Savina T.A., Suprun T.Yu. Extra pulmonary tuberculosis at HIV-positive people. Tuberculosis and Lung Diseases. 2007; 84 (7): 16-9 (in Russ.).
7. Crothers K., Thompson B.W., Burkhardt K., Morris A., Flores S.C., Diaz P.T. et al. HIV-associated lung infections and complications in the era of combination antiretroviral therapy. Lung HIV Study. Seattle, Washington: University of Washington; 2011; 19.

8. Rasokat H.H., Hautkr Z. Skin changes in drug-dependent patients. Probl. Drug Depend. 1990; 65 (4): 351-4.

9. Savel'eva T.,V, Trofimova T.N., Rassokhina V.V. Radiodiagnosis of changes of an abdominal cavity and zabryushinny space at HIV-positive patients. HIV Infection and Immunosuppressive Disorders. 2010; 2 (3): 15-22 (in Russ.).

10. Skopin M.S., Batyrov F.A., Kornilova Z.Kh. Prevalence of tuberculosis of abdominal organs and feature of its identification. Tuberculosis and Lung Diseases. 2007; 84 (1): 22-6 (in Russ.).

11. Gaus A.A., Klimova N.V., Darvin V.V., Zinchenko 0.A. Possibilities of a multispiral computer tomography in justification of the choice of surgical tactics of treatment of peritonitis at patients with a terminal stage of HIV infection. Surgut State University Journal. 2016; 4 (30): 17-22 (in Russ.).

12. Bluvshteyn G.A., Mozerov S.A., Kulakov A.A. Clinical and morphological aspects of surgical mistakes and complications at sick HIV/AIDS. University Proceedings. Volga Region. Medical Sciences. 2010; 4 (16): 61-72 (in Russ.).

\section{Сведения об авторах | Information about the authors}

Климова Наталья Валерьевна, д. М. Н., профессор кафедры госпитальной хирургии, заведующая рентгенологическим отделением, БУ ХМАО - Югры «Сургутская окружная клиническая больница»; orcid.org/0000-0003-2407-8534

Гаус Анна Алексеевна, к. м. н., доцент кафедры госпитальной хирургии, БУ ВО ХМАО - Югры «Сургутский государственный университет»; orcid.org/0000-0002-7434-1540

Дарвин Владимир Васильевич, д. м. Н., профессор, заведующий кафедрой госпитальной хирургии, БУ ВО ХМАО - Югры «Сургутский государственный университет»; orcid.org/0000-0002-2506-9798

Ильина Ульяна Богдановна*, врач-рентгенолог, БУ ХМАО Югры «Сургутская окружная клиническая больница»; orcid.org/0000-0002-6782-9863

E-mail:krusan.ub@gmail.com
Natal'ya V. Klimova, Dr. Med. Sc., Professor of Hospital Surgery Chair, Head of Radiology Department, Surgut District Clinical Hospital; orcid.org/0000-0003-2407-8534

Anna A. Gaus, Cand. Med. Sc., Associate Professor of Hospital Surgery Chair, Surgut State University; orcid.org/0000-0002-7434-1540

Vladimir V. Darvin, Dr. Med. Sc., Professor, Chief of Hospital Surgery Chair, Surgut State University; orcid.org/0000-0002-2506-9798

Ul'yana B. Il'ina*, Radiologist, Surgut District Clinical Hospital; orcid.org/0000-0002-6782-9863

E-mail: krusan.ub@gmail.com 